\title{
Vicariance and Oceanic Barriers Drive Contemporary Genetic Structure of Widespread Mangrove Species Sonneratia alba J. Sm in the Indo-West Pacific
}

\author{
Alison K. S. Wee ${ }^{1,2,3}$ D , Jessica Xian Hui Teo ${ }^{2}$, Jasher L. Chua ${ }^{2}$, Koji Takayama ${ }^{4}$, \\ Takeshi Asakawa ${ }^{5}$, Sankararamasubramanian H. Meenakshisundaram ${ }^{6}$, Onrizal ${ }^{7}$, Bayu Adjie ${ }^{8}$, \\ Erwin Riyanto Ardli ${ }^{9}$, Sarawood Sungkaew ${ }^{10}$, Monica Suleiman ${ }^{11}$, Nguyen Xuan Tung ${ }^{12}$, \\ Severino G. Salmo III ${ }^{13}$ (D), Orlex Baylen Yllano ${ }^{14}$, M. Nazre Saleh ${ }^{15}$, Khin Khin Soe ${ }^{16}$, \\ Yoichi Tateishi ${ }^{17}$, Yasuyuki Watano ${ }^{5}$, Yoshiaki Tsuda ${ }^{18}$, Tadashi Kajita ${ }^{3, *}$ (D) and \\ Edward L. Webb 2,*
}

1 Guangxi Key Laboratory of Forest Ecology and Conservation, College of Forestry, Guangxi University, Daxuedonglu 100, Nanning 530004, China; alisonwks@gxu.edu.cn

2 Department of Biological Sciences, National University of Singapore, Singapore 117543, Singapore; blazingstar91@gmail.com (J.X.H.T.); rehsaj@gmail.com (J.L.C.)

3 Iriomote Station, Tropical Biosphere Research Center, University of the Ryukyus, 870 Uehara, Taketomi-cho, Yaeyama-gun, Okinawa 907-1541, Japan

4 Museum of Natural and Environmental History, Shizuoka, 5762 Oya, Suruga-ku, Shizuoka-shi, Shizuoka 422-8017, Japan; gen33takayama@gmail.com

5 Department of Biology, Graduate School of Science, Chiba University, 1-33 Yayoi-cho, Inage-ku, Chiba 263-8522, Japan; asakawa@faculty.chiba-u.jp (T.A.); watano@faculty.chiba-u.jp (Y.W.)

6 Biotechnology Programme, M.S. Swaminathan Research Foundation, Chennai 600113, India; justforscience@gmail.com

7 Faculty of Forestry, Universitas Sumatera Utara, Medan 20155, Indonesia; onrizal@gmail.com

8 Bali Botanical Garden, Indonesian Institute of Sciences, Bali 82191, Indonesia; biobayu@gmail.com

9 Faculty of Biology, Jenderal Soedirman University, Purwokerto 53122, Indonesia; eriantoo@yahoo.com

10 Forest Biology Department, Faculty of Forestry, Kasetsart University, Bangkok 10900, Thailand; sarawoodsungkaew@yahoo.com

11 Institute for Tropical Biology and Conservation, Universiti Malaysia Sabah, Kota Kinabalu 88400, Malaysia; monicas@ums.edu.my

12 Mangrove Ecosystem Research Centre, Hanoi National University of Education, Hanoi 123112, Vietnam; xt_xuthanh@yahoo.com

13 Department of Environmental Science, School of Science and Engineering, Ateneo de Manila University, Quezon City 1108, Philippines; ssalmo@ateneo.edu

14 Biology Department, College of Science and Technology, Adventist University of the Philippines, Silang, Cavite 4118, Philippines; obyupd@yahoo.com

15 Department of Forest Management, Faculty of Forestry, Universiti Putra Malaysia, Serdang 43400, Malaysia; mnazre@gmail.com

16 Department of Botany, University of Yangon, Yangon 11041, Myanmar; khinkhinsoe9@gmail.com

17 Faculty of Education, University of the Ryukyus, Sembaru 903-0129, Japan; mame@edu.u-ryukyu.ac.jp

18 Sugadaira Research Station, Mountain Science Center, University of Tsukuba, 1278-294 Sugadairakogen, Ueda, Nagano 386-2204, Japan; ytsuda.gt@gmail.com

* Correspondence: kajita@mail.ryudai.jp (T.K.); ted.webb@nus.edu.sg (E.L.W.); Tel.: +81-656-516-4184 (T.K.); Fax: +81-65-6779-2486 (T.K.)

Received: 19 October 2017; Accepted: 30 November 2017; Published: 6 December 2017

\begin{abstract}
Patterns of genetic structure are essential for a comprehensive understanding of the evolution and biogeography of a species. Here, we investigated the genetic patterns of one of the most widespread and abundant mangrove species in the Indo-West Pacific, Sonneratia alba J. Sm., in order to gain insights into the ecological and evolutionary drivers of genetic structure in mangroves. We employed 11 nuclear microsatellite loci and two chloroplast regions to genotyped 25 . alba
\end{abstract}


populations. Our objectives were to (1) assess the level of genetic diversity and its geographic distribution; and (2) determine the genetic structure of the populations. Our results revealed significant genetic differentiation among populations. We detected a major genetic break between Indo-Malesia and Australasia, and further population subdivision within each oceanic region in these two major clusters. The phylogeographic patterns indicated a strong influence of vicariance, oceanic barriers and geographic distance on genetic structure. In addition, we found low genetic diversity and high genetic drift at range edge. This study advances the scope of mangrove biogeography by demonstrating a unique scenario whereby a widespread species has limited dispersal and high genetic divergence among populations.

Keywords: biogeography; gene flow; genetic diversity; genetic divergence; phylogeography; sea dispersal

\section{Introduction}

Mangroves are widespread, tropical and subtropical coastal plant communities with strong genetic structures that are mainly shaped by their biogeographic history. Major mangrove plant lineages were separated into the Atlantic East Pacific (AEP) and the Indo-West Pacific (IWP) regions after the closure of the Tethys Sea, and subsequently evolved in independent trajectories, resulting in different species assembly in each region [1]. The striking similarities in genetic patterns across species within each region indicated that vicariance events, Quaternary climatic oscillation and oceanic currents may have a universal effect on the geographic distribution of genetic variation [2]. For example, the most distinctive genetic break in the AEP region divides mangrove populations into the Atlantic and Pacific Oceans. This was observed in all studied mangrove species in the AEP and is attributed to vicariance following the final closure of the Central American Isthmus [2,3]. Similarly in the IWP, the Malay Peninsula, which separates the East Indian Ocean (EIO) and South China Sea (SCS), was found to be a strong genetic barrier for many mangrove species. The genetic divide was thought to be caused by the geographic separation between populations in the Pacific Ocean from those in the Indian ocean that was imposed by the land mass during past glacial maxima [4]. In addition, mangroves from the IWP also exhibited phylogeographic congruency across species, whereby populations were genetically differentiated according to three subregions: the EIO, SCS and Northern Australia (NA), thus suggesting limited gene flow across these subregions [4-6]. These phylogeographic congruencies in co-distributed mangroves not only enabled the identification of geographic factors (e.g., land barriers) that shaped the genetic structure, but also provided insights into past dynamics of mangrove forest cover.

Despite phylogeographic concordance at the regional scale, detailed genetic structure often differ across mangrove species. For instance, the exact location of the genetic divide between Pacific and Indian oceans was situated exactly between both coasts of the Malay Peninsula in Bruguiera gymnorhiza (L.) Lam. [4] but between the edge of the Andaman Sea and the Strait of Malacca in Rhizophora mucronata Lam. $[7,8]$. This discordance reflects the contribution of taxon-specific traits to the fine-scaled genetic structure, e.g., the unexpected location of the genetic divide in R. mucronata was attributed to its high capabilities in long distance dispersal and the importance of ocean currents in driving it. This finding highlights the importance of contemporary processes (i.e., oceanic connectivity) in dictating the genetic structure. There is therefore a need to study the detailed genetic structure of major mangrove lineages, using range-wide sampling design and rapidly-mutating molecular markers, in order to gain a comprehensive understanding on the evolutionary history and trajectories of mangroves.

Sonneratia alba is a major component species of mangroves and a member of the mangrove lineage in Lythraceae. It has one of the widest geographic distributions, occurring from East Africa through 
the Indo-Malay archipelago to the Pacific islands $[9,10]$. A recent study on the phylogeography of $S$. $a l b a$, using sequence data of seven nuclear loci (designed from expressed sequence tags of its close relative, Sonneratia caseolaris (L.) Engl.) and three chloroplast DNA regions, largely agreed with the EIO versus SCS versus NA genetic clusters found in other mangroves. The genetic structure of S. alba showed two major lineages corresponding to the Indo-Malesia and Australasia regions that diverged ca. 3.15 million years ago, prior to Pleistocene [11]. A later divergence estimated at 1.87 million years ago was detected within the Indo-Malesia region, resulting in a lineage within the South China Sea and another spread out across the region. This study clearly demonstrated the strong influence of Pleistocene sea-level fluctuations on the genetic structure. However, due to the slower mutation rate in the single nucleotide polymorphism loci employed by Yang et al. (2017) and the inherent low levels of genetic diversity in S. alba [11,12], the data may be limited when it comes to inferences on the fine-scale genetic patterns, especially contemporary gene flow mirrored by more recent demographic history. This is essential in understanding the biogeography of $S$. alba, as most of the studied populations are connected by sea in the present day, and gene flow can be more extensive than glacial periods.

This study aims to determine the patterns of population connectivity in $S$. alba across its native range and to identify biogeographic/phylogeographic barriers that may shape these patterns. Our purpose is to enhance the resolution of the genetic structure of $S$. alba using molecular marker with higher mutation rates. We employed eleven polymorphic nuclear microsatellite (SSR) loci to genotype 25 S. alba populations ranging from Mozambique to New Caledonia (Table 1). We supplemented the SSR data by genotyping two chloroplast regions in 23 populations. Specifically, our objectives were to (1) assess the level of genetic diversity and its geographic distribution and (2) determine the genetic structure of the populations using both individual-based and population-based genetic analyses. With the wide distribution of $S$. alba and its representation of the mangrove lineage in Lythraceae, its post-glacial genetic structure would be crucial to understand the legacy of vicariance and the influence of the taxon-specific traits on the genetic connectivity in mangroves from the IWP region.

Table 1. Location information for all populations.

\begin{tabular}{|c|c|c|c|c|c|c|}
\hline Pop. Code & $\mathbf{N}$ & Location & Country & Major Region-Minor Region & Latitude & Longitude \\
\hline MO1 & 34 & Espinho & Mozambique & WIO & $17^{\circ} 45^{\prime} 38^{\prime \prime} \mathrm{S}$ & $37^{\circ} 11^{\prime} 36^{\prime \prime} \mathrm{E}$ \\
\hline $\mathrm{MO} 2$ & 17 & Zalala Beach & Mozambique & WIO & $17^{\circ} 47^{\prime} 43^{\prime \prime} \mathrm{S}$ & $37^{\circ} 04^{\prime} 33^{\prime \prime} \mathrm{E}$ \\
\hline MY1 & 25 & Myanmar & Myanmar & EIO-Andaman Sea & $15^{\circ} 48^{\prime} 39^{\prime \prime} \mathrm{N}$ & $95^{\circ} 16^{\prime} 09^{\prime \prime} \mathrm{E}$ \\
\hline MY2 & 32 & Myanmar & Myanmar & EIO-Andaman Sea & $12^{\circ} 23^{\prime} 53^{\prime \prime} \mathrm{N}$ & $98^{\circ} 34^{\prime} 11^{\prime \prime} \mathrm{E}$ \\
\hline TH1 & 23 & Phuket & Thailand & EIO-Strait of Malacca & $08^{\circ} 24^{\prime} 28^{\prime \prime} \mathrm{N}$ & $98^{\circ} 30^{\prime} 42^{\prime \prime} \mathrm{E}$ \\
\hline TH2 & 36 & Kantang & Thailand & EIO-Strait of Malacca & $07^{\circ} 19^{\prime} 13^{\prime \prime} \mathrm{N}$ & $99^{\circ} 29^{\prime} 27^{\prime \prime} \mathrm{E}$ \\
\hline MA1 & 10 & Langkawi & Malaysia & EIO-Strait of Malacca & $06^{\circ} 25^{\prime} 14^{\prime \prime} \mathrm{N}$ & $99^{\circ} 49^{\prime} 19^{\prime \prime} \mathrm{E}$ \\
\hline MA2 & 35 & Linggi & Malaysia & EIO-Strait of Malacca & $02^{\circ} 23^{\prime} 34^{\prime \prime} \mathrm{N}$ & $101^{\circ} 58^{\prime} 42^{\prime \prime} \mathrm{E}$ \\
\hline SIN & 24 & SungeiBuloh & Singapore & EIO-Strait of Malacca & $01^{\circ} 26^{\prime} 54^{\prime \prime} \mathrm{N}$ & $103^{\circ} 43^{\prime} 51^{\prime \prime} \mathrm{E}$ \\
\hline IN1 & 29 & Cilacap & Indonesia & EIO-East Indian Ocean & $07^{\circ} 42^{\prime} 33^{\prime \prime} \mathrm{S}$ & $108^{\circ} 54^{\prime} 00^{\prime \prime} \mathrm{E}$ \\
\hline IN2 & 22 & Bali & Indonesia & EIO-Java Sea & $08^{\circ} 44^{\prime} 01^{\prime \prime} \mathrm{S}$ & $115^{\circ} 11^{\prime} 48^{\prime \prime} \mathrm{E}$ \\
\hline MA3 & 31 & Kuantan & Malaysia & SCS & $03^{\circ} 47^{\prime} 57^{\prime \prime} \mathrm{N}$ & $103^{\circ} 19^{\prime} 33^{\prime \prime} \mathrm{E}$ \\
\hline TH3 & 25 & Nam Chiao & Thailand & SCS & $12^{\circ} 09^{\prime} 57^{\prime \prime} \mathrm{N}$ & $102^{\circ} 28^{\prime} 36^{\prime \prime} \mathrm{E}$ \\
\hline VIE & 41 & Ca Mau & Vietnam & SCS & $08^{\circ} 42^{\prime} 51^{\prime \prime} \mathrm{N}$ & $104^{\circ} 48^{\prime} 58^{\prime \prime} \mathrm{E}$ \\
\hline MA4 & 24 & Sabah & Malaysia & SCS & $05^{\circ} 59^{\prime} 25^{\prime \prime} \mathrm{N}$ & $116^{\circ} 05^{\prime} 29^{\prime \prime} \mathrm{E}$ \\
\hline PH1 & 27 & Batangas & Philippines & SCS & $13^{\circ} 58^{\prime} 11^{\prime \prime} \mathrm{N}$ & $120^{\circ} 37^{\prime} 33^{\prime \prime} \mathrm{E}$ \\
\hline PH2 & 12 & Panay & Philippines & SCS & $11^{\circ} 48^{\prime} 09^{\prime \prime} \mathrm{N}$ & $122^{\circ} 12^{\prime} 26^{\prime \prime} \mathrm{E}$ \\
\hline JAP & 34 & Iriomote & Japan & NPO & $24^{\circ} 16^{\prime} 50^{\prime \prime} \mathrm{N}$ & $123^{\circ} 52^{\prime} 58^{\prime \prime} \mathrm{E}$ \\
\hline PA1 & 31 & Palau & Palau & $\mathrm{NPO}$ & $07^{\circ} 30^{\prime} 13^{\prime \prime} \mathrm{N}$ & $134^{\circ} 32^{\prime} 09^{\prime \prime} \mathrm{E}$ \\
\hline PA2 & 36 & Palau & Palau & $\mathrm{NPO}$ & $07^{\circ} 22^{\prime} 04^{\prime \prime} \mathrm{N}$ & $134^{\circ} 34^{\prime} 35^{\prime \prime} \mathrm{E}$ \\
\hline MIC & 33 & Kosrae & Micronesia & $\mathrm{NPO}$ & $05^{\circ} 21^{\prime} 03^{\prime \prime} \mathrm{N}$ & $163^{\circ} 01^{\prime} 12^{\prime \prime} \mathrm{E}$ \\
\hline AU1 & 37 & Daintree & Australia & NA & $16^{\circ} 16^{\prime} 45^{\prime \prime} \mathrm{S}$ & $145^{\circ} 26^{\prime} 22^{\prime \prime} \mathrm{E}$ \\
\hline AU2 & 34 & Ludmila Creek & Australia & NA & $12^{\circ} 24^{\prime} 30^{\prime \prime} \mathrm{S}$ & $130^{\circ} 49^{\prime} 57^{\prime \prime} \mathrm{E}$ \\
\hline NC1 & 31 & Baie de Tare & New Caledonia & $\mathrm{SPO}$ & $22^{\circ} 15^{\prime} 48^{\prime \prime} \mathrm{S}$ & $167^{\circ} 00^{\prime} 57^{\prime \prime} \mathrm{E}$ \\
\hline NC2 & 32 & Canala & New Caledonia & $\mathrm{SPO}$ & $21^{\circ} 30^{\prime} 23^{\prime \prime} \mathrm{S}$ & $165^{\circ} 58^{\prime} 12^{\prime \prime} \mathrm{E}$ \\
\hline
\end{tabular}

WIO: West Indian Ocean; EIO: East Indian Ocean; SCS: South China Sea; NPO: Northwest Pacific Ocean; NA: Northern Australia; SPO: Southwest Pacific Ocean. 


\section{Materials and Methods}

\subsection{Study Species}

Sonneratia alba is an opportunistic species with high tolerance for extreme coastal environments, occurring in the lower intertidal zones and downstream estuarine areas (Figure 1a), and often withstanding high hydrodynamic energy [9], inundation [13] and salinities [14]. It has been observed as the first species to colonize mudflats and subsequently reduce wave attenuation for the establishment of other mangrove species [15]. Sonneratia alba is diploid, highly fecund and has non-viviparous fruits (Figure 1c). The flower has approximately 300 white long stamens (Figure 1b) and is pollinated by nectivorous bats and hawkmoths $[9,16]$. Each flower produces a fruit with more than 100 small, woody, sickle-shaped seeds that are released when the fruit disintegrates following prolonged immersion in saline or brackish water [14] (Figure 1d,e). The dispersal capability of Sonneratia propagules is one of the least studied major mangrove species. It is possible that Sonneratia propagules experience a two-step dispersal, first by the fruits, and then by the seeds that are released following fruit decay (Figure 1d,e). Observations and anecdotal evidence suggests that although both fruits and seeds have a certain extent of initial buoyancy when they first enter the water column, the seeds themselves may have a short flotation period and thus a low potential for long distance dispersal.

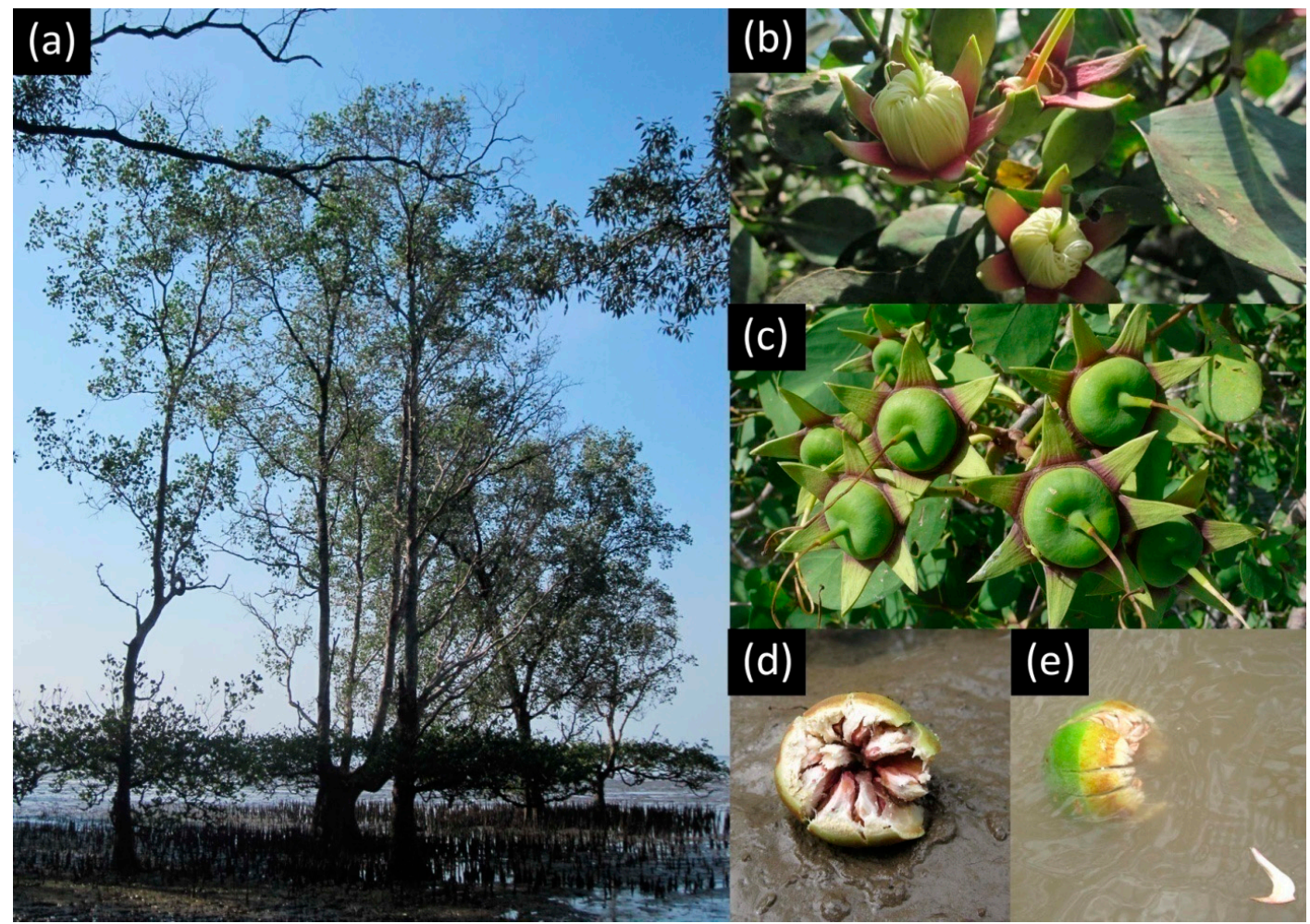

Figure 1. Photos of Sonneratia alba showing (a) mature trees at the lower intertidal zone; the even layer of leaf growth at the lower trunk indicates the level of high tide; (b) flowers; (c) fruits; (d) a fallen fruit that landed during low tide; and (e) a seed being released from a decaying fruit and dispersed by the outgoing tide.

\subsection{Plant Material}

Leaf samples of 715 individuals of $S$. alba were collected from 25 populations in the IWP region (Table 1, Figure 2a). The collected leaf material was desiccated with silica gel and stored at room temperature until use. 
(a)

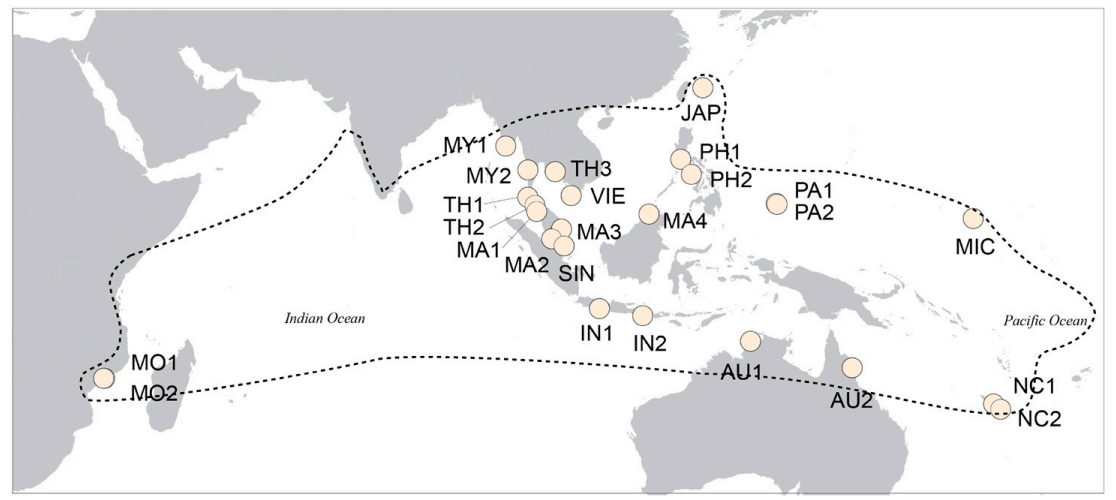

(b)

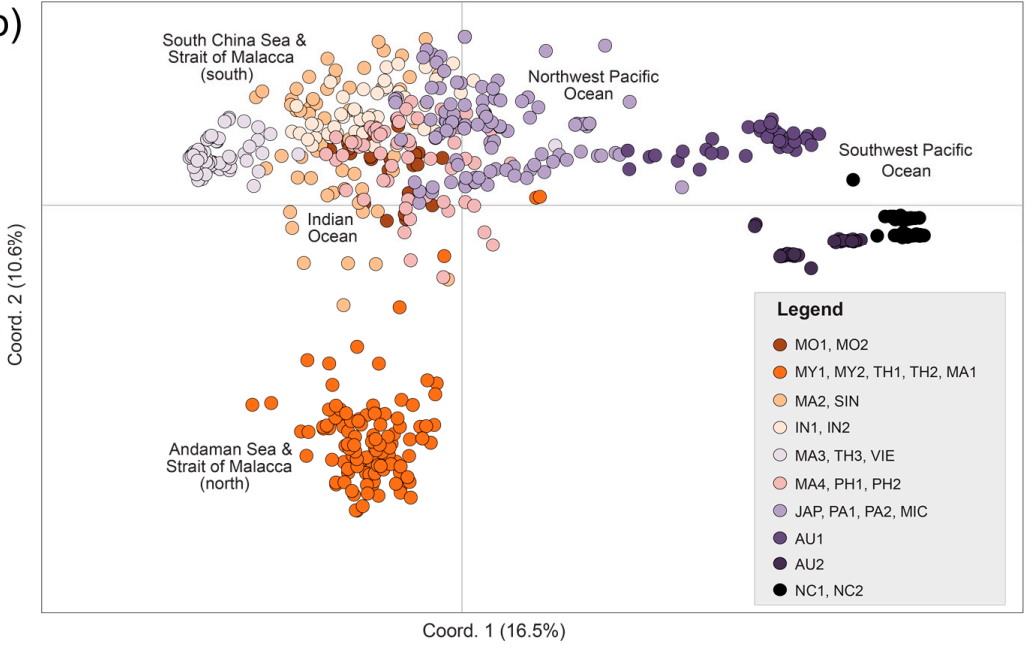

Figure 2. (a) Map showing the location of sampled populations. Population names are defined in Table 1. Dotted line denotes the species distribution. (b) The genetic clusters of S. alba as shown by individual-based principal coordinate analysis ( $\mathrm{PCoA})$ scatter plots. The percentage of total variation attributed to each axis of the PCoA plot is indicated. Two minor clusters were separated from the majority, one consisting of individuals from Andaman Sea and northern Strait of Malacca (orange) and the other consisting of individuals from Southwest Pacific Ocean (dark purple and black).

\subsection{DNA Extraction and Genotyping}

Genomic DNA was extracted from silica-dried leaf tissue following a modified cetyltrimethylammonium bromide (CTAB) extraction method [17].

Eleven microsatellite markers for S. alba developed by [18] were selected based on their level of polymorphism and ease of multiplexing: SA102, SA103, SA105, SA106, SA108, SA110, SA112, SA113, SA115, SA117 and SA123. All loci were genotyped using fluorescent-labeled primers with the following dye-primer combinations-6-FAM: SA102, SA103, SA112 and SA11; VIC: SA105 and SA106; NED: SA108, SA110, SA117 and SA123; and PET: SA113.Polymerase chain reaction (PCR) was performed using Qiagen Multiplex PCR Kit (Qiagen, Hilden, Germany) in a final volume of $5 \mu \mathrm{L}$ with $1 \mu \mathrm{L}$ of DNA. The PCR profile used was initial denaturation of $5 \mathrm{~min}$ at $94{ }^{\circ} \mathrm{C} ; 35$ cycles of $45 \mathrm{~s}$ at $95^{\circ} \mathrm{C}$, $45 \mathrm{~s}$ at $50{ }^{\circ} \mathrm{C}, 45 \mathrm{~s}$ at $72{ }^{\circ} \mathrm{C}$; and a final elongation of $10 \mathrm{~min}$ at $72{ }^{\circ} \mathrm{C}$. Electrophoresis of the amplified DNA was performed with an ABI 3130xl automated sequencer (Applied Biosystems, Foster City, CA, USA) using standard settings. Fragment length was assigned by the GENEMAPPER 4.1 software (Applied Biosystems, Foster City, CA, USA) using GeneScan-600 LIZ size standard. Genotype data of MY4 (Sabah) were obtained from a published primer note [18].

PCR amplifications were performed on one to five representative samples from each population (a total of 102 individuals) using two cpDNA regions: rpl20-rps12 spacer [19] and 
rpl16-F71-rpl16-R1516 intron [20]. Populations IN1 and MA4 were not included due to repeated failure to amplify the two cpDNA regions. We designed internal primer rpl20-int1F, rpl20-int1R, rpl20-int2F, rpl20-int2R, rpl16-int1F, rpl16-int1R, rpl16-int2F, rpl16-int2R, rpl16-int3F and rpl16-int3R (see Table S1 for details) for ease in sequencing. PCR was performed using TaKaRa Ex Taq polymerase (TaKaRa Bio Inc., Shiga, Japan) with the following conditions: initial denaturation for 5 min at $94{ }^{\circ} \mathrm{C}$; 30 cycles of $45 \mathrm{~s}$ at $94{ }^{\circ} \mathrm{C}, 1 \mathrm{~min}$ at $50{ }^{\circ} \mathrm{C}, 30 \mathrm{~s}$ at $72{ }^{\circ} \mathrm{C}$; and a final elongation for $5 \mathrm{~min}$ at $72{ }^{\circ} \mathrm{C}$. The total reaction volume was $10 \mu \mathrm{L}$, of which $1.0 \mu \mathrm{L}$ was DNA. PCR products were purified using $10 \mu \mathrm{L}$ of Exosap-IT (Affymetrix, Santa Clara, CA, USA) before cycle sequencing. The total reaction volume for cycle sequencing was $10 \mu \mathrm{L}$ of which $2 \mu \mathrm{L}$ was DNA. Cycle sequencing products were purified with AxyPrep Mag Dye Cleanup Kits (Axygen Scientific Inc., Union City, CA, USA), following the manufacturer's protocol. The sequencing reaction was performed on an ABI 3130xl automated sequencer (Applied Biosystems, Foster City, CA, USA). We sequenced a total of approximately $750 \mathrm{bp}$ and $800 \mathrm{bp}$ of the rpl20-rps12 spacer (rpl20 from here on) and rpl16-F71-rpl16-R1516 intron region (rpl16 from here on), respectively.

\subsection{Nuclear Microsatellite Data Analysis}

Deviations from Hardy-Weinberg equilibrium (HWE) were tested for each locus and population by an exact test implemented in computer program FSTAT 2.9.3 (hereafter, FSTAT) [21]. To check the presence of null alleles and its bias on data analysis, null allele frequencies were estimated for each locus and population by the expectation maximization algorithm [22] implemented in FreeNA [23]. In addition, population pairwise $F_{\mathrm{ST}}$ [24] was calculated with the original genotype data and with data corrected for null alleles following the "excluding null alleles" (ENA) method using the FreeNA. Since the uncorrected pairwise $F_{\mathrm{ST}}$ values were included within the $95 \%$ confidence interval of the pairwise $F_{\mathrm{ST}}$ values corrected for null alleles by FreeNA (see Table S2 for details), we used the original genotype data in this study.

Genetic diversity was evaluated at the species and population levels in terms of the allelic richness based on 10 diploid individuals, the gene diversity and the fixation index $\left(F_{\mathrm{IS}}\right)$ using FSTAT. The significance of the deviation of $F_{\text {IS }}$ values from 0 was estimated for each locus and across the loci for each population on the basis of 1000 randomizations using FSTAT. The percentage of polymorphism, number of private alleles, observed heterozygosity $\left(H_{\mathrm{O}}\right)$ and expected heterozygosity $\left(H_{\mathrm{E}}\right)$ were calculated using the software GENALEX 6.5 [25].To assess the presence of recent bottlenecks in the populations, we employed Wilcoxon's signed rank test using BOTTLENECK software [26]. We tested for significant excess in expected heterozygosity (indicator of recent bottleneck) under the assumptions that all loci fit the infinite allele mutation model (IAM), the two-phase model (TPM, under which 70\% of the mutations are single-step and 30\% multi-step) and the strict Stepwise Mutation Model (SMM).

The population differentiation was evaluated by calculating the $F_{\mathrm{ST}}$ value [24] and the 95 and $99 \%$ confidence intervals of the value derived from 1000 bootstraps. Pairwise $F_{\mathrm{ST}}$ values were also calculated, and their significance was tested by randomizing multilocus genotypes between the two populations with standard Bonferroni corrections. In addition, we calculated the pairwise $F^{\prime}$ ST values, which accounted for the underestimation of genetic differentiation under the conditions of low genetic diversity [27]. These calculations were conducted using FSTAT and GENALEX 6.5.

A principal coordinate analysis (PCoA) was performed with GENALEX 6.5 software using the genotypic distance between all individual pairs.

We then assessed the genetic structure with a Bayesian model-based clustering algorithm implemented in the software STRUCTURE v. 2.3.3 [28]. By employing a combination of the admixture model and the F-model [29] with the Locprior option [30], 30 runs were performed for each number of subpopulations $(K)$, from $K=1$ to $K=15$. Each run consisted of 30,000 replicates of the Markov chain Monte Carlo (MCMC) after a burn-in of 20,000 replicates. The distribution of the probability of data (Ln P(D)) along $K$ and the $\Delta K$ [31] were evaluated using the STRUCTURE HARVESTER online program [32]. Multimodality among runs and the clustering pattern at each $K$ were summarized using 
the Clustering Markov Packager Across K (CLUMPAK) online program [33]. The mean $F$ value for each cluster (analogue to $F_{\mathrm{ST}}$ between each cluster and common ancestor [29]) across the run was calculated based on the runs which showed major clustering by CLUMPAK. The genetic relationships among clusters were evaluated using the genetic distance calculated by STRUCTURE. We employed the genetic distance from the results which showed the highest $\mathrm{Ln} P(D)$ among the run with major clustering pattern at each $K$. The neighbour-joining (NJ) trees for the clusters were generated using Population 1.2.30 [34].

To determine the geographic locations of putative genetic barriers, we used the Monmonier's algorithm implemented in Barrier v2.2 [35] and the pairwise population genetic distance values (Nei's $D_{\mathrm{A}}$ ) generated by Population 1.2.30. We computed the locations of genetic barriers under the scenario of one, five and seven genetic barriers (corresponding to $K=2, K=6$ and $K=8$, respectively), based on the results from the STRUCTURE analysis.

Aside from the spatial analysis performed in Barrier, the presence of a genetic barrier can also be tested by regressing a matrix of pairwise genetic distance (Nei's $D_{\mathrm{A}}$ ) between populations from either side of the barrier to a predictor matrix of complete genetic divergence between them. As previous research demonstrated varying influence of the Malay Peninsula on gene flow (inferred from genetic structure) [4], we tested the significance of the Malay Peninsula as a genetic barrier by using twelve populations (six from either side of the peninsula) from our dataset that represented both coasts of the peninsula. The EIO populations (west coast Malay Peninsula) were represented by MY1, MY2, TH1, TH2, MA1 and MA2. The SCS populations (east coast Malay Peninsula) were represented by MA3, TH3, VIE, MA4, PH1 and PH2. In the predictor matrix, population pairs from different coasts were coded 1 (high expected genetic differentiation), while population pairs from the same coast were coded 0 (low expected genetic differentiation) [7,36]. A Mantel R statistic based on Pearson's product-moment correlation between the pairwise genetic distance matrix and the predictor matrix was performed with 999 permutations using the package "vegan" [37] implemented in the R statistical platform. As genetic divergence may be influenced by geographic distance, a partial Mantel test was performed in which the distance effect was factored out.

We used two analyses to examine for the genetic composition of edge populations. The first analysis tested for the correlation between genetic parameters and latitude, while the second tested for the difference in genetic parameters between core and peripheral populations. In the former, we performed simple linear regression between $A_{\mathrm{R}}, H_{\mathrm{O}}$ or $F_{\mathrm{IS}}$ and latitude using the $\mathrm{R}$ statistical platform. In the latter, we divided all populations into two categories, core populations $(n=13$, $<10^{\circ}$ in latitude) and peripheral populations $\left(n=12,>10^{\circ}\right.$ in latitude). We used FSTAT to perform a 2-sided comparison (10,000 permutations) of $A_{\mathrm{R}}, H_{\mathrm{O}}, H_{\mathrm{S}}$ (gene diversity), $F_{\mathrm{IS}}$ and $F_{\mathrm{ST}}$ between core and peripheral populations.

\subsection{Chloroplast Sequence Data Analysis}

The cpDNA sequences were analyzed using SEQSCAPE 2.7 software (Applied Biosystems, Foster City, CA, USA). Peak calling was corrected manually. Multiple sequence alignment was carried out with default settings in the built-in CLUSTALW program in MEGA 7.0 software [38]. Phylogenetic analysis was performed using the final concatenated sequences of $1088 \mathrm{bp}$ (433 bp and $655 \mathrm{bp}$ of rpl20 and rpl16, respectively) using maximum parsimony (MP) and maximum likelihood (ML) methods implemented in MEGA 7.0. Branch support of MP was assessed by bootstrap analysis based on 1000 replicates using the subtree-pruning-regrafting search option with 10 random addition sequence replicates. For ML analysis, we used the default settings in the software jModelTest [39] to evaluate the likelihoods of 88 models of nucleotide sequence evolution. The best-fitting model that can be implemented in MEGA 6.0 was chosen as the Hasegawa-Kishino-Yano model [40] according to the Bayesian Information Criterion.ML bootstrap tests were performed with 1000 replicates, with initial trees generated by BIONJ, a modified neighbor-joining method [41]. 


\section{Results}

\subsection{Data Quality}

Missing data accounted for only $0.7 \%$ of the microsatellite data set. Significant deviations from HWE at $p<0.05$ were detected in 13 out of 275 population-locus comparisons after Bonferroni corrections (see Table S3 for details). All of the significant deviations from HWE were homozygote excess, none of which was associated with a particular locus or population. Hence, all loci were used in subsequent analysis. Null alleles were potentially implicated in $27.6 \%$ of all population-locus combinations, with the highest estimated frequency of 0.28 , found in SA106 in population TH1 (see Table S4 for details).

\subsection{Genetic Diversity}

All microsatellite loci were polymorphic, with the total number of alleles ranging from six to 21 per locus (see Table S5 for details). The genetic diversity indices for each population are shown in Table 2. Moderate genetic diversity was observed in S. alba; the average observed heterozygosity $\left(H_{\mathrm{O}}\right)$ and expected heterozygosity $\left(H_{\mathrm{E}}\right)$ at the species level was 0.271 and 0.327 , respectively. However, significant levels of inbreeding $\left(F_{\mathrm{IS}}\right)$ was found in two thirds of the populations (Table 2), indicating a general homozygote excess in this species. The alleles were often fixed within a population, with nine out of 25 populations having at least five monomorphic loci. In total, 38 private alleles (26.2\% of the total number of alleles) distributed across 18 populations were detected, with one-third of them residing within AU1 and AU2 (Table 2).Genetic bottleneck was only detected in three populations: MA1, MIC and NC1 (Table 2).

Table 2. Genetic diversity parameters of sampled populations. Population names are defined in Table 1.

\begin{tabular}{cccccccc}
\hline Pop. Code & $\boldsymbol{A}_{\mathbf{R}}$ & $\boldsymbol{P}_{\mathbf{A}}$ & $\boldsymbol{H}_{\mathbf{O}}$ & $\boldsymbol{H}_{\mathbf{E}}$ & $\boldsymbol{H}_{\mathbf{S}}$ & $\boldsymbol{F}_{\mathbf{I S}}$ & Bottleneck \\
\hline MO1 & 1.637 & 0 & $0.099 \pm 0.033$ & $0.192 \pm 0.061$ & 0.196 & $0.496^{*}$ & No \\
MO2 & 1.338 & 0 & $0.011 \pm 0.007$ & $0.068 \pm 0.038$ & 0.072 & $0.850^{*}$ & No \\
MY1 & 1.739 & 0 & $0.095 \pm 0.042$ & $0.146 \pm 0.063$ & 0.150 & $0.366^{*}$ & No \\
MY2 & 2.645 & 2 & $0.256 \pm 0.063$ & $0.332 \pm 0.076$ & 0.339 & $0.245^{*}$ & No \\
TH1 & 2.902 & 1 & $0.206 \pm 0.065$ & $0.378 \pm 0.085$ & 0.390 & $0.473^{*}$ & No \\
TH2 & 2.911 & 1 & $0.347 \pm 0.087$ & $0.351 \pm 0.09$ & 0.357 & 0.025 & No \\
MA1 & 1.455 & 1 & $0.273 \pm 0.129$ & $0.178 \pm 0.070$ & 0.183 & -0.492 & Yes \\
MA2 & 3.055 & 1 & $0.413 \pm 0.059$ & $0.454 \pm 0.055$ & 0.461 & 0.104 & No \\
SIN & 2.944 & 1 & $0.405 \pm 0.059$ & $0.429 \pm 0.060$ & 0.439 & 0.077 & No \\
IN1 & 2.474 & 2 & $0.273 \pm 0.038$ & $0.412 \pm 0.056$ & 0.422 & $0.353^{*}$ & No \\
IN2 & 3.747 & 2 & $0.589 \pm 0.066$ & $0.565 \pm 0.065$ & 0.578 & -0.019 & No \\
MA3 & 1.655 & 0 & $0.065 \pm 0.040$ & $0.111 \pm 0.061$ & 0.114 & $0.433^{*}$ & No \\
TH3 & 1.883 & 2 & $0.136 \pm 0.053$ & $0.203 \pm 0.071$ & 0.209 & $0.348^{*}$ & No \\
VIE & 1.760 & 2 & $0.086 \pm 0.038$ & $0.160 \pm 0.054$ & 0.164 & $0.471 *$ & No \\
MA4 & 1.702 & 2 & $0.242 \pm 0.082$ & $0.234 \pm 0.077$ & 0.239 & -0.015 & No \\
PH1 & 3.775 & 1 & $0.496 \pm 0.048$ & $0.581 \pm 0.056$ & 0.594 & $0.166^{*}$ & No \\
PH2 & 3.311 & 0 & $0.465 \pm 0.057$ & $0.461 \pm 0.055$ & 0.482 & 0.036 & No \\
JPN & 2.069 & 0 & $0.219 \pm 0.042$ & $0.380 \pm 0.071$ & 0.388 & $0.435^{*}$ & No \\
PA1 & 4.062 & 2 & $0.531 \pm 0.036$ & $0.615 \pm 0.042$ & 0.626 & $0.153^{*}$ & No \\
PA2 & 3.622 & 2 & $0.523 \pm 0.077$ & $0.549 \pm 0.052$ & 0.557 & 0.061 & No \\
MIC & 3.157 & 2 & $0.413 \pm 0.063$ & $0.506 \pm 0.066$ & 0.515 & $0.197^{*}$ & Yes \\
AU1 & 3.26 & 5 & $0.278 \pm 0.076$ & $0.385 \pm 0.102$ & 0.393 & $0.292^{*}$ & No \\
AU2 & 2.293 & 8 & $0.162 \pm 0.068$ & $0.241 \pm 0.096$ & 0.245 & $0.341 *$ & No \\
NC1 & 1.678 & 0 & $0.091 \pm 0.068$ & $0.127 \pm 0.087$ & 0.130 & $0.301 *$ & Yes \\
NC2 & 1.862 & 1 & $0.097 \pm 0.063$ & $0.117 \pm 0.077$ & 0.120 & 0.191 & No \\
Mean & 2.517 & 1.5 & $0.271 \pm 0.016$ & $0.327 \pm 0.017$ & 0.335 & & \\
\hline
\end{tabular}

$A_{\mathrm{R}}$, allelic richness rarefied to a minimum of 10 diploid individuals; $P_{\mathrm{A}}$, total number of private alleles $H_{\mathrm{O}}$, observed heterozygosity; $H_{\mathrm{E}}$, expected heterozygosity; $H_{\mathrm{S}}$, gene diversity; $F_{\mathrm{IS}}$, inbreeding coefficient; ${ }^{*}$ significant at $p<0.05$. 


\subsection{Population Differentiation and Genetic Structure}

Significant population differentiation $\left(F_{\mathrm{ST}}\right)$ averaged across all loci and populations was estimated at 0.568 (95\% CI: $0.477-0.65,99 \%$ CI: 0.447-0.670). Pairwise population $F_{\mathrm{ST}}$ estimates ranged from 0.076 between neighbouring TH1 and TH2 to 0.888 between MO2 and NC1 at opposite ends of the distribution range (Table 3). All $F_{\mathrm{ST}}$ values were significant at $p<0.01$ after Bonferroni correction. All pairwise $F_{\text {ST }}^{\prime}$ values, which accounted for the underestimation of genetic differentiation under the conditions of low genetic diversity, were higher than the pairwise $F_{\mathrm{ST}}$ values of the same population pair (see Table S6 for details).

The genetic differentiation on an individual basis based on a principal coordinate analysis (PCoA) resulted in distinct clusters of individuals, with one major cluster consisting of most individuals, and two minor geographically-relevant clusters consisting of individuals from (1) the Andaman Sea and northern Strait of Malacca; and (2) Southwest Pacific Ocean (Figure 2b).

The Bayesian model-based clustering analysis (STRUCTURE) revealed the largest increase in the Ln $\mathrm{P}(\mathrm{D})$ from $K=1$ to 2 and the highest $\Delta K$ at $K=2$ (see Figure S1 for details). Moreover, the Ln P(D) continued to increase slightly up to $K=15$, with higher values of $\Delta K$ detected under $K=6$ and 8 (see Figure S1 for details). Therefore, the genetic structure at $K=2,6$ and 8 was employed and discussed in this study. Although multimodality among runs was found at each $K$, the major clustering pattern showed hierarchical genetic structure through $K$. Hence, we described only the results from the major patterns in this study. The major clustering pattern at $K=2$ inferred two clusters matching a main geographical disjunction between populations from Northern Australia and Southwest Pacific Ocean (Cluster II; purple), and the other populations (Cluster I; beige) (Figure 3a). Most individuals were assigned with high probability to one of the clusters with the exception of individuals from JPN which showed a mixed ancestry of the two clusters. Concordantly, we detected (via the BARRIER analysis) the presence of a genetic barrier stretching across the Timor Sea, Arafura Sea, and Torres Strait towards the Pacific Ocean, separating these two genetic clusters (Figure 3a). The F value of Cluster I (Northern Australia and Southwest Pacific Ocean) was lower than that of Cluster II, suggesting a smaller effect of genetic drift in the latter.

At $K=6$ and 8 , the subgroups identified were compatible with the two groups revealed under $K=2$, with more genetic subdivision that was consistent with geographical distribution (Figure 3b). In both $K=6$ and 8 , populations from the West Indian Ocean (MO1 and MO2) genetically differentiated from the rest, with IN1 consistently exhibiting mixed ancestry with this subgroup (Figure 3b,c). Similarly, two populations from the Andaman Sea (MY1, MY2) and three populations from the northern Strait of Malacca (TH1, TH2, MA1) formed another subgroup comprising only one genetic ancestry. The Northern Australia and Southwest Pacific Ocean cluster was observed to clearly divided into populations from Australia (AU1 and AU2) and New Caledonia (NC1 and NC2). In contrast, extensive mixed ancestry was observed in populations from southern Strait of Malacca (MA2 and SIN) and Java Sea (IN2). Although JPN was categorized as a population from the Northwest Pacific Ocean, it appeared to not share the same genetic ancestry as the other three populations from the same region (PA1, PA2 and MIC). These results corresponded closely with those from the genetic barrier analysis (BARRIER), whereby the location of the additional four genetic barriers were identified to be (1) in the Indian Ocean, (2) in the southern region of Strait of Malacca, (3) across the Luzon Strait between the South and East China Seas, (4) across the Sulu Sea (Figure 3b). Higher $F$ values ( $>0.5)$ were found in clusters corresponding to the Indian Ocean (MO1, 2), South China Sea (MA3, TH3, VIE), and New Caledonia (NC1 and 2). 
Table 3. Pairwise $F_{\mathrm{ST}}$ between population pairs (below diagonal) and significance values after Bonferroni correction (above diagonal).

\begin{tabular}{|c|c|c|c|c|c|c|c|c|c|c|c|c|c|c|c|c|c|c|c|c|c|c|c|c|c|}
\hline & 01 & I & Y1 & $Y 2$ & $\mathrm{H1}$ & $\mathrm{H} 2$ & 1 & MA2 & {$[\mathbf{N}$} & V1 & J2 & IA3 & H3 & IE & IA4 & PH1 & H2 & PN & A1 & A2 & IIC & U1 & U2 & JC1 & NC2 \\
\hline 01 & & & $*$ & $* *$ & $* *$ & * & ** & $* * *$ & $* * *$ & * & ** & $* *$ & ** & $* *$ & $* * *$ & * & $* * *$ & $* * *$ & $* *$ & 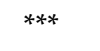 & $* *$ & $* * *$ & $* * *$ & 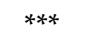 & $* * *$ \\
\hline $\mathrm{O} 2$ & 319 & & & * & & & & & & & & & & & & & & & & & & & & & ** \\
\hline Y1 & 705 & 0.819 & & $* *$ & & & $* *$ & * & & & ** & & & & & & & & & & & & & & ** \\
\hline Y2 & 634 & 684 & 0.377 & & & & ** & $* * *$ & & & ** & & & & & & & & & & & & & & ** \\
\hline H1 & 629 & 664 & 0.372 & 0.206 & & ** & ** & ** & & & ** & ** & & $* *$ & & & & & & & & & & & ** \\
\hline $\mathrm{H} 2$ & 608 & 645 & 0.327 & 0.142 & 0.076 & & $* * *$ & ** & & & ** & ** & & ** & & * & 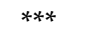 & & & & & & & & ** \\
\hline A1 & 768 & 863 & 646 & 426 & 352 & 0.344 & & & & & & ** & & ** & & & ** & & & & & & & & ** \\
\hline A2 & 593 & 612 & 0.564 & 428 & 400 & 0.391 & 0 & & & & ** & ** & & ** & & & & & & & & & & & ** \\
\hline 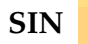 & 621 & & 0.643 & 14 & 478 & 484 & & 35 & & $* * *$ & ** & $* *$ & & $* *$ & & & & & & & & & & & ** \\
\hline II & 17 & 27 & & & & & & 24 & & & & $* * *$ & & & & & & & & & & & & & \\
\hline IN2 & 0. & 4 & & & 2 & & & & 6 & & & $* * *$ & & ** & & $* * *$ & & & & & & & & 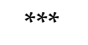 & ** \\
\hline MA3 & 759 & 49 & 4 & 4 & 36 & & & & & & 0 & & $x *$ & $* * *$ & & & & & & $* *$ & & & & $* * *$ & ** \\
\hline TH3 & 0.679 & 69 & 02 & 69 & 52 & & & 50 & 00 & & 32 & 62 & & $* * *$ & & & & & & & & & & 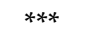 & ** \\
\hline VIE & 0.698 & 0.772 & 60 & 27 & 32 & 73 & & 77 & 93 & & & 14 & 0 & & & & & ** & & $* *$ & & & & $x+4$ & ** \\
\hline MA4 & 0.722 & 0.769 & 0.746 & 531 & 612 & 596 & 36 & 0.449 & 76 & 76 & 73 & 719 & 627 & 0.667 & & $* * *$ & & & & & & & & $* * *$ & ** \\
\hline PH1 & 0.444 & 484 & 0.494 & 393 & 367 & 0.384 & 0.481 & 0.307 & 74 & 39 & 0.228 & 18 & 0.422 & 0.513 & 14 & & $\neq * *$ & & & & & & & $* * *$ & ** \\
\hline PH2 & 0.611 & 685 & 0.619 & 0.513 & 450 & 0.463 & 0.571 & 0.406 & 0.379 & 0.349 & 0.286 & 0.659 & 0.537 & 0.665 & 0.569 & 0.238 & & $* * *$ & $* * *$ & $* * *$ & & & ** & $* * *$ & $* *$ \\
\hline PN & 0.597 & 641 & 0.660 & .560 & 517 & 0.548 & 0.664 & 0.489 & 0.513 & 0.496 & 0.410 & 0.639 & 0.588 & 0.644 & 0.626 & 0.372 & 0.501 & & & $* * *$ & & & & $* * *$ & $* *$ \\
\hline PA1 & 0.496 & 499 & 0.536 & 450 & 412 & 0.437 & 0.461 & 0.296 & 0.285 & 0.336 & 0.239 & 0.544 & 0.455 & 0.527 & 0.482 & 0.292 & 0.331 & 0.446 & & $* * *$ & $* *$ & $* * *$ & $* * *$ & $* * *$ & **** \\
\hline PA2 & 0.524 & 507 & 0.580 & .485 & 442 & 0.470 & 0.521 & 0.343 & 326 & 0.425 & 0.271 & 0.545 & 465 & 0.533 & 0.483 & 0.311 & 0.366 & 0.488 & I.174 & & ** & $* * *$ & $* *$ & $* * *$ & $* * *$ \\
\hline MIC & 559 & 572 & 0.588 & .515 & 464 & 0.484 & 0.539 & 0.361 & 330 & 0.364 & 0.317 & 0.588 & .501 & 0.564 & 0.509 & 0.325 & 0.361 & 0.524 & 0.228 & 0.309 & & $* * *$ & $* * *$ & $* * *$ & $* * *$ \\
\hline AU1 & 666 & 688 & 0.707 & 619 & 587 & 607 & 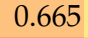 & & 62 & 52 & 0.479 & 0.704 & 659 & 0.714 & & & 0.517 & & 57 & 0.468 & & & $* * *$ & $* * *$ & $* * *$ \\
\hline AU2 & 751 & 794 & 0.760 & 667 & 654 & 0.661 & 0.7 & 0.631 & 663 & 0.660 & 0.599 & 11 & .766 & 0.793 & 51 & 0.583 & 0.669 & & & 0.571 & 0.606 & 0.555 & & $* * *$ & $* * *$ \\
\hline NC1 & 0.820 & 880 & 0.845 & .745 & 722 & 709 & 0.8 & 0.650 & 0.702 & 0.716 & 0.646 & 0.863 & .819 & 0.836 & 04 & 0.617 & 0.725 & 0.697 & 0.604 & 0.601 & 0.646 & 0.658 & 0.729 & & $* * *$ \\
\hline $\mathrm{NC2}$ & 0.824 & 0.888 & 0.851 & 0.748 & 0.716 & 0.711 & 0.841 & 0.675 & 0.725 & 0.724 & 0.662 & 0.871 & 0.825 & 0.841 & 0.810 & 0.637 & 0.734 & 0.716 & 0.612 & 0.603 & 0.655 & 0.661 & 0.738 & 0.504 & \\
\hline
\end{tabular}

Population names are defined in Table 1 . Warmer colours (red and orange) represent higher $F_{\mathrm{ST}}$ values; cooler colours (green) represent lower $F_{\mathrm{ST}}$ values. ${ }^{* *}$ and ${ }^{* * *}$ indicates statistical significance at $p<0.01$ and $p<0.001$, respectively. 


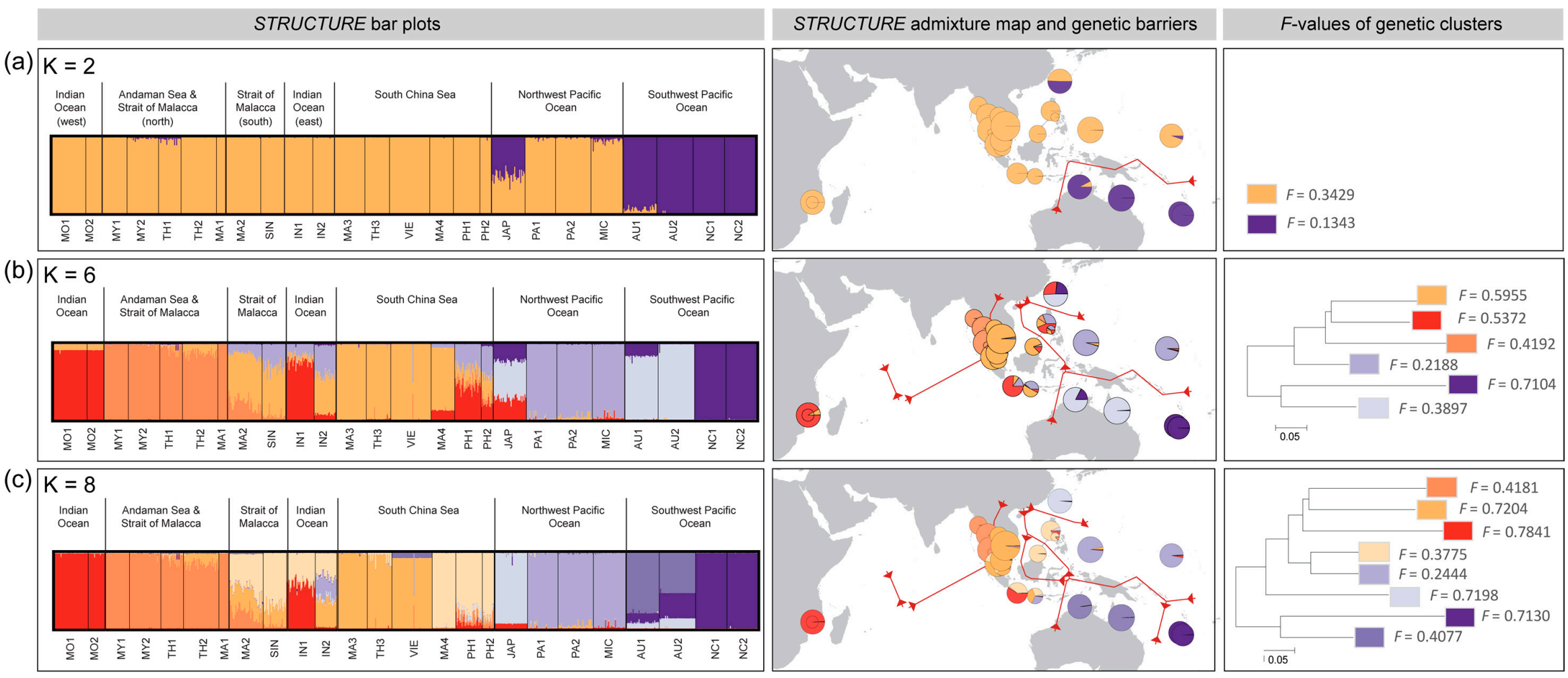

Figure 3. Bayesian clustering analysis of the 25 populations of $S$. alba at (a) $K=2 ;(\mathbf{b}) K=6$; and (c) $K=8$ scenarios, shown as barplots indicating the putative genetic ancestry of each individual (left), and admixture maps (centre) and neighbour-joining phylograms (right). The size of the pie charts in the admixture maps indicates population size. The $F$-value of each genetic cluster is indicated on the NJ phylogram. The maps were generated using QGIS Desktop v2.18.10 [42] with country shape files downloaded from DIVA-GIS [43]. 
In $K=8$, the mixed ancestry in JPN was no longer observed and the population emerged as a unique subgroup (Figure 3c). Two additional genetic barriers, one isolating the Bornean population (MA4) and another isolating the New Caledonia populations (NC1, NC2) were identified on top of the five genetic barriers found under the $K=6$ scenario.

Concordant to the PCoA, the NJ trees at $K=6$ and 8 revealed genetic differentiation between populations from the Southwest Pacific Ocean and the remaining populations clusters (Figure $3 b, c)$; the genetic clusters were divided into two groups corresponding to the Indo-Malesia and Australasia subregions.

The Mantel test on the influence of Malay Peninsula on genetic structure revealed significant correlation between the predictor matrix and the pairwise genetic differentiation before $(R=0.552$, $p<0.001)$ and after $(R=0.480, p<0.01)$ the effects of geographic distance was accounted for. Hence, the genetic structure of $S$. alba presented an east-west divide across the Malay Peninsula.

Analyses on the genetic composition of edge populations revealed lower genetic diversity, higher inbreeding and higher genetic differentiation at range limits. Linear regression between $A_{\mathrm{R}}, H_{\mathrm{O}}$ or $F_{\mathrm{IS}}$ and latitude revealed no correlation, significant negative correlation and significant positive correlation, respectively (Figure 4). On the other hand, the two-sided comparison between core and peripheral populations performed in FSTAT revealed significant differences between these core and edge population groups in observed heterozygosity, inbreeding coefficient and genetic differentiation (Table 4).

Table 4. Two-sided comparison between core and peripheral populations, on mean allelic richness $\left(A_{\mathrm{R}}\right)$, observed heterozygosity $\left(H_{\mathrm{O}}\right)$, gene diversity $\left(H_{\mathrm{S}}\right)$, inbreeding coefficient $\left(F_{\mathrm{IS}}\right)$ and genetic differentiation $\left(F_{\mathrm{ST}}\right)$. Comparisons for $H_{\mathrm{O}}, F_{\mathrm{IS}}$ and $F_{\mathrm{ST}}$ are significant (bold) at $p<0.05$.

\begin{tabular}{cccccc}
\hline & $\boldsymbol{A}_{\mathbf{R}}$ & $\boldsymbol{H}_{\mathbf{O}}$ & $\boldsymbol{H}_{\mathbf{S}}$ & $\boldsymbol{F}_{\mathbf{I S}}$ & $\boldsymbol{F}_{\mathbf{S T}}$ \\
\hline Core & 2.727 & 0.334 & 0.394 & 0.152 & 0.449 \\
Peripheral & 2.291 & 0.191 & 0.272 & 0.298 & 0.66 \\
$p$-value & 0.193 & 0.031 & 0.070 & 0.031 & 0.010 \\
\hline
\end{tabular}



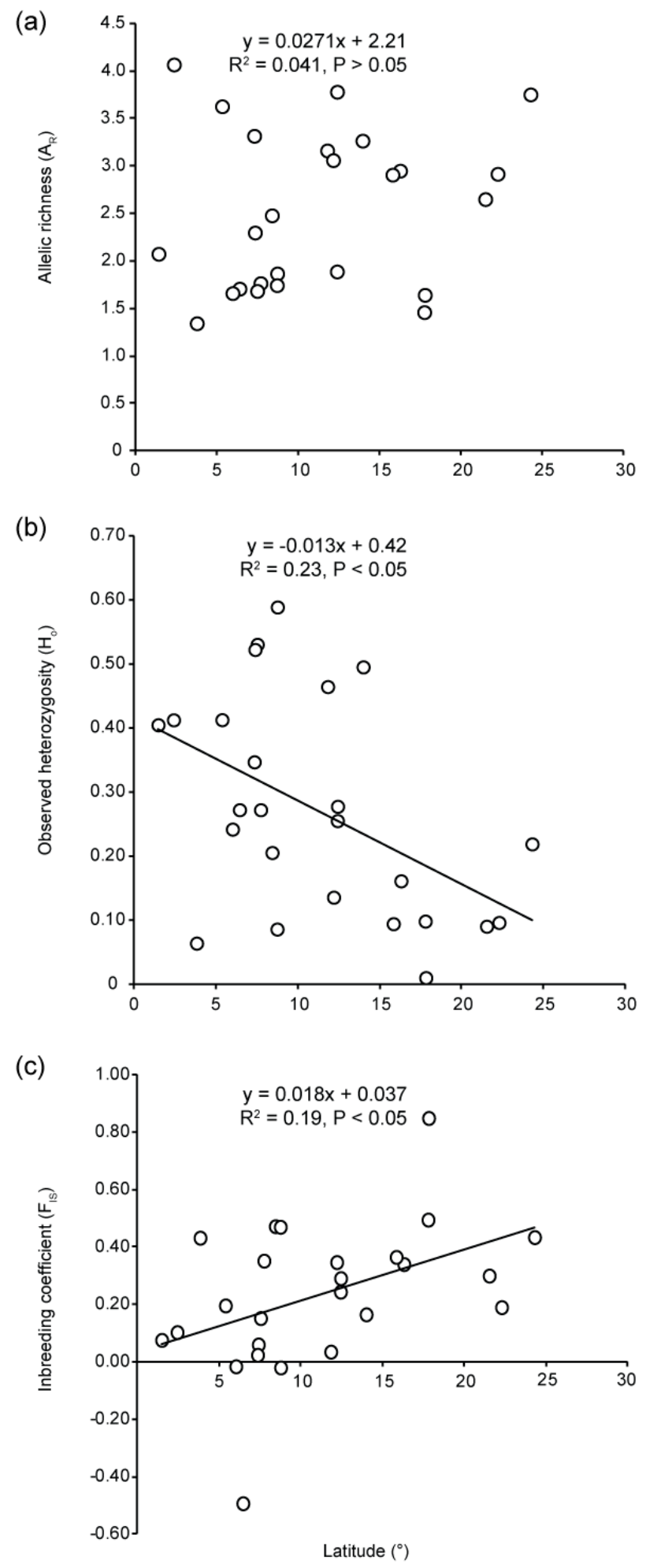

Figure 4. Correlation tests between latitude and (a) allelic richness; (b) observed heterozygosity and (c) inbreeding coefficient of all populations. Each open circle represents one population. Significant negative and positive correlation was detected for observed heterozygosity and inbreeding coefficient, respectively. The regression lines for these significant correlations were shown on the respective graphs. 


\subsection{Chloroplast DNA Variations}

Excluding mononucleotide length polymorphism, three cpDNA haplotypes were detected using the concatenated sequences of rpl16 and rpl20, with only three variant sites found in $1088 \mathrm{bp}$. Haplotype $\mathrm{C}$ occurred across the distribution range, while haplotypes $\mathrm{A}$ and $\mathrm{B}$ were only found in populations from the South China Sea (MA3, TH3, VIE, PH1 and PH2) and New Caledonia (NC1 and NC2), respectively (Figure 5). The same tree topology and general branch support were recovered in MP and ML analyses, both supporting a deeper division between haplotype A, and haplotype $\mathrm{B}$ and C, than between haplotype B and C (Figure 5 inset).Due to the low number of haplotypes discovered, we used the cpDNA results mainly to supplement the findings from the SSR data.

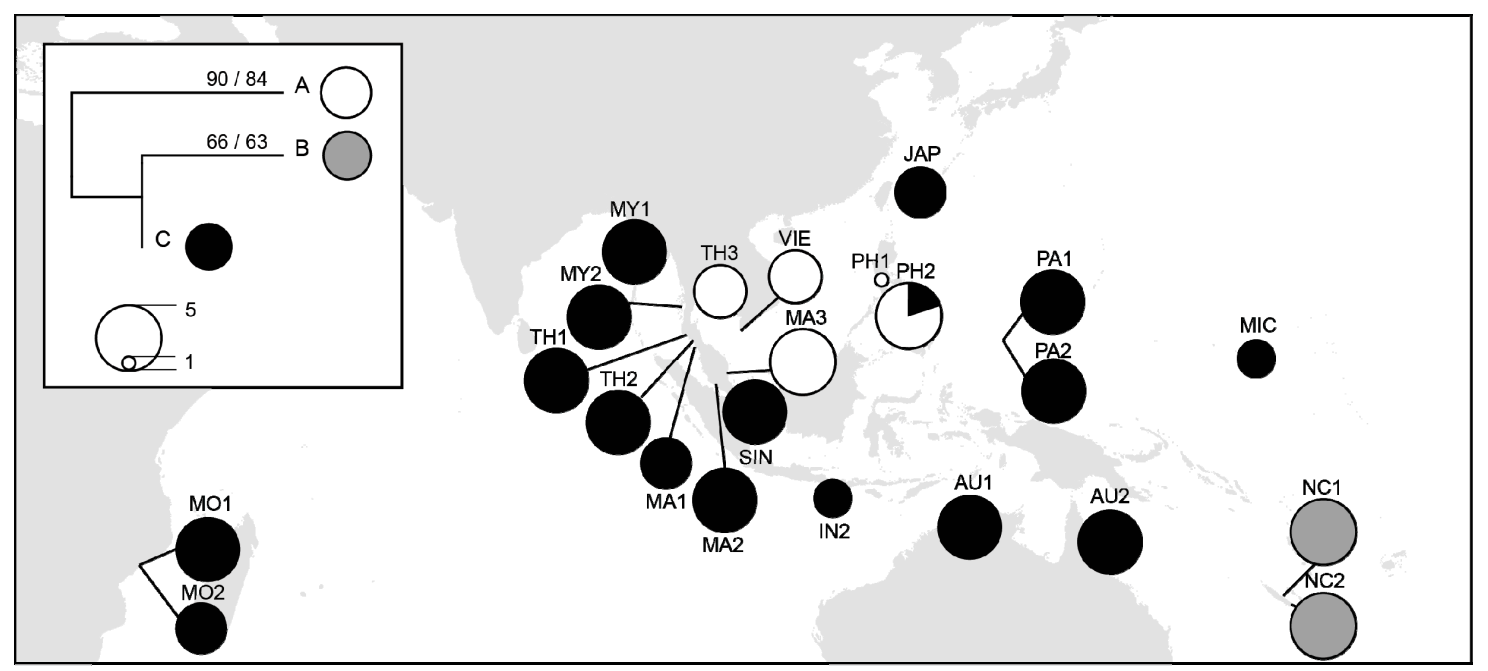

Figure 5. Geographical distributions of the three cpDNA haplotypes of $S$. alba. The size of the pie charts indicates sample size of the population. Population namesare defined in Table 1 . The inset (upper left) denotes the phylogenetic tree; numbers at the nodes indicate MP bootstrap support/ML bootstrap support. The map was generated using QGIS Desktop v2.18.10 [42] with country shape files downloaded from DIVA-GIS [43].

\section{Discussion}

\subsection{Majorphylogeographic Break between Indo-Malesia and Australasia}

Our SSR and cpDNA data revealed significant genetic differentiation among populations in S. alba, and hence an absence of panmixia across its distribution. An important feature of our results is the occurrence of a main phylogeographic break between populations from Northern Australia and Southwest Pacific Ocean cluster, and the other populations from the IWP (Table 3; Figure 3a). This complements the findings of Yang et al. (2017) [11]. Even though the genetic divergence between populations from North Australia to Southwest Pacific Ocean and the rest of IWP has been observed in other mangrove species, it was never the strongest genetic break range wide, except for in R. stylosa [8]. Populations from Australia were observed to be genetically close to populations from the South China Sea in Ceriops spp. [5], to populations from the Indian Ocean in R. mucronata [44], and to populations in the Northwest Pacific Ocean in R. apiculata [44]. The presence of this major genetic break in S. alba (and R. stylosa) may be explained by a periodic land barrier during glacial periods in the past 250,000 years, which lies between Australia and New Guinea, across the present Timor Sea, Arafura Sea and Torres Strait [45]. During interglacial periods, a complex system of westward-flowing sea surface currents across the western equatorial Pacific Ocean moved through the Torres Strait [46], potentially acting as a cryptic barrier. Together, this historical land barrier and contemporary oceanic barrier may result 
in the divergence between populations in this region of the Southern Hemisphere with the rest of the IWP.

\subsection{Strong Influence of Vicariance and Oceanic Barriers on Genetic Structure}

Both our SSR and cpDNA data supported a genetic divide between SCS and EIO, as previously observed in S. alba [11] and other mangrove species (see Introduction). We specifically tested for the effect of the Malay Peninsula as a genetic barrier with and without accounting for distance, and found a significant effect in both instances. However, the geographic distribution of cpDNA haplotypes in our study revealed that the Malay Peninsula did not dichotomously divide lineages between the Indian and Pacific Ocean. Instead, the haplotype in the Indian Ocean could be found throughout the distribution range, while another haplotype was largely confined within the South China Sea. The seclusion of the South China Sea haplotype in our study agreed with the findings from Yang et al. (2017) [11], though our cpDNA data did not demonstrate two clades corresponding to the Indo-Malesia and Australasia regions.

The combination of a wider geographic sampling (especially from marginal populations in the Southwest Pacific, Myanmar and Mozambique) and the usage of faster-mutating molecular markers (hence higher genetic diversity) in our study allowed for a broader and more refined biogeographic analysis than afforded in the recent study of S. alba by Yang et al. (2017) [11]. Notably, on top of EIO-SCS divergence, our data also supported further subdivision of population structuring within the EIO and SCS. These subdivisions were not detected in a previous study by Yang et al. (2017) [11], and highlighted the potential importance of oceanic barriers in restricting gene flow (see also [7]).

In particular, populations from the Andaman Sea and northern Strait of Malacca were found to be highly insular, though to a lesser extent than the populations from Northern Australia and Southwest Pacific Ocean (Table 3; Figures $2 b$ and $3 b, c$ ). The genetic divergence observed in populations from the Andaman Sea and northern Strait of Malacca could similarly be attributed to vicariance. During glacial periods, larger areas of the Andaman and Nicobar islands were exposed, partially enclosing the Andaman Sea into a basin [45], potentially limiting gene flow between the mangrove refugia within the basin and the populations beyond it. Contemporary populations from the Andaman Sea and northern Strait of Malacca were likely colonized by individuals from the refugia during interglacial periods. Our Bayesian analysis revealed that the populations from the northern and southern Strait of Malacca were from different genetic lineages, possibly as a result of this vicariance. Nevertheless, gene flow was detected between these two lineages, suggesting that recent post-glaciation contact counteracted the strong effects of vicariance. It is interesting to note that the phylogeographic pattern observed here differed from that of $R$. mucronata, for which a genetic continuity was detected at the boundary between the Andaman Sea and the Malacca Strait [7]. In S. alba, the boundary was pushed further south into the Malacca Strait. Such inter-species disparity in phylogeographic pattern can result from differences in dispersal potential, habitat specificity, and level of exposure to tidal flow [47].

Similarly, the clear dichotomous division in the Northern Australia and Southwestern Pacific Ocean cluster (AU1-AU2 versus NC1-NC2) and the South China Sea cluster (MA3-TH3-VIE versus MA4-PH1-PH2) under the $K=8$ scenario in both the Bayesian analysis and the Barrier analysis indicated the presence of cryptic oceanic barriers. The strong genetic differentiation between Northern Australia and Southwestern Pacific Ocean cluster was supported by both SSR and cpDNA data. Our study agreed with the phylogeography of reef fishes, whereby populations from the Micronesian islands (Northwest Pacific Ocean) were more connected to Northern Australia than the Melanesia (Southwest Pacific Ocean) (See Figure 2b) [48]. This suggests that the oceanic separation between Australia and New Caledonia imposed by the Coral Sea is large enough to build up significant population structure, even for marine species with high dispersability. Likewise, populations from the South China Sea were genetically divided into mainland-origin (MA3-TH3-VIE) and island-origin (MA4-PH1-PH2) (Figure 3c); thus, the sea itself appeared to be a genetic barrier. This genetic pattern has been observed in S. alba itself [11] and also in viviparous mangrove species, Kandeliacandel [49]. 
In the former, the divergence was attributed to glacial isolation of northern Borneo by exposed land surrounding the Sulu Sea [11]. In the latter, the divergence was attributed to the fruiting season that coincided with northward-flowing ocean currents cutting through the South China Sea into the Pacific Ocean, thus preventing dispersal between populations from the east and west corners of the South China Sea [49]. Landscape level propagule release simulations, which account for ocean circulation patterns, will be able to cross-validate these inferences [50].

Our present data also revealed the presence of an admixture zone in the Java Sea and southern Strait of Malacca, as supported by two lines of evidence: (1) populations MA2, SIN and IN2 consistently showing mixed ancestry in the STRUCTURE analysis under $K=6$ and $K=8$ scenarios (Figure 3b,c); and (2) these populations having relatively low pairwise genetic differentiation with other populations in IWP (Table 3). The observed admixture zone is strategically located at the crossroad between the Indian and Pacific Oceans and hence may be receiving genetic input from different neighbouring genetic clusters. Indeed, the well-known genetic break between these two oceans can be more precisely placed at a mere 300-400 km stretch across the Java and Flores Sea [51,52]. Although significant genetic differentiation was detected across the Java and Flores Sea, populations in this region were commonly found to include haplotypes from either side of the genetic break $[53,54]$. This highlights the contemporary role of the admixture zone in homogenizing genetic divergence between the Indian and Pacific Oceans, potentially reducing lineage diversification.

\subsection{Restricted Gene Flow}

Our findings revealed unexpectedly restrictive gene flow in $S$. alba. Aside from the admixture zone in the Java Sea and southern Strait of Malacca, gene flow has been largely restricted to within an oceanic region. Furthermore, we detected significant genetic differentiation in all pairwise $F_{\mathrm{ST}}$ comparisons, even between neigbouring populations. This signifies a profound limiting gene flow in this species, and lends support to previous claims that $S$. alba propagules have limited buoyancy and dispersal distance. Although pollen dispersal by nectarivorous bats could potentially result in long distance gene flow, it is still limited to linear coastlines or between islands in close proximity.

Our findings thus question the importance of long distance dispersal and its role in colonization. How can a species with dispersal seemingly so constrained by geographic distance achieve such a widespread distribution? One possible explanation is the ability of S. alba to withstand higher inundation and salinity, which results in its niche occupancy at lower intertidal zones. Being close to the seafront means that the propagules of $S$. alba are more accessible to the open ocean and are hence easily dispersed by outgoing tides. Indeed, local retention due to physical barriers is a main impediment for dispersal in the marine environment [55]. In mangroves, local retention by trapping agents (e.g., mangrove aerial roots) could be so limiting as to influence dispersal distance, dispersal patterns [56] and even the zonation of vegetation [57]. In addition to being at the seafront, S. alba has one of the smallest propagules among mangrove species, hence it is likely that $S$. alba propagules experience low local retention and a high possibility of dispersal beyond the population. Another factor that could contribute to the widespread distribution of $S$. alba is its high fecundity. The sea dispersal syndrome can be exceptionally successful for colonization [58], which can occur even with very small number of founding individuals [59]. Long distance dispersal by chance has been detected in propagules with limited dispersal capabilities, often by means of rafting [60]. Although S. alba propagules may have low buoyancy, their high numbers increase the chance of rare long distance dispersal events. The highly local gene dispersal found in S. alba thus highlights the potential importance of ecological traits such as niche occupancy at the lower intertidal zone, small propagule size and high fecundity to counteract the effects of limited dispersal distance, resulting in S. alba being one of the most successful mangrove species. 


\subsection{Low Genetic Diversity and High Genetic Drift at Range Edge}

In general, the genetic diversity of $S$. alba was low, with an average gene diversity of 0.335. This corresponded with the lower nucleotide diversity across populations detected in Zhou et al. (2011) [12] and Yang et al. (2017) [11], both of which attributed this to a demographic history involving recent colonization, migration and local adaptation. Such consistently low level of genetic diversity could also be a character mirrored by long species history [61].

Our results demonstrated that populations of $S$. alba at higher latitudes were characterized by lower heterozygosity and higher levels of inbreeding, with no apparent decrease in allelic richness. With the exception of MA3, the five populations with the lowest genetic diversity were marginal populations from Mozambique (MO2), New Caledonia (NC1 and 2) and Myanmar (MY1). In contrast, higher genetic diversity was found in populations closer to the equator, around the central area of the species range, e.g., such as Indonesia (IN2), Philippines (PH1) and Palau (PA1 and 2). Highly divergent loci despite low heterozygosity have been detected in S. alba previously [11,12]. Here, we confirmed that this pattern is present in marginal populations across the entire distribution range.

In this study, we detected more detailed genetic diversity and structure, especially in marginal populations, than in Yang et al. (2017) [11]. Even at low genetic diversity, we observed polymorphism in all the marginal populations while Yang et al. (2017) found no polymorphism in several marginal populations [11]. For example, a high number of private alleles was detected in the population from Daintree in this study (AU1) while no polymorphism was detected by Yang et al. (2017) [11]. in the same population. This highlights the importance of employing loci with high variability in studying genetically impoverished species.

Lower genetic diversity at range limits is common in mangroves [62-64]. The low level of genetic diversity of $S$. alba at range margins was previously attributed to low effective population size due to demographic instability, repeated bottleneck and founder effect [11]. However, our results contrast with these previous findings [62-64] as higher inbreeding at range limits was not affiliated to a significantly impoverished allelic diversity in S. alba. With the exception of populations from the SCS, the highest $F$-values were detected in genetic clusters located at range edges (populations from Mozambique, New Caledonia and Japan), indicating strong genetic drift in marginal populations. The absence of a bottleneck effect in all marginal populations (except for NC1) indicated that the genetic drift detected could not be attributed to recent demographic contraction. Therefore, the most likely explanation would be founder effects coupled to low gene flow. Marginal populations are usually gene flow sinks that receive migrants from core populations [65]. Stronger founder effects at range edge could be attributed to repeated range contraction and expansion following glacial-interglacial cycles [11]. Furthermore, suitable habitats are scarce at range edges, thus increasing the isolation of marginal populations and reducing gene flow among them.

\section{Conclusions}

Our study represents a comprehensive assessment of the global phylogeography of S. alba. By sampling throughout its entire distribution range, we demonstrated that gene flow in this species is highly restricted by genetic barriers and geographic distance despite having a widespread distribution and dispersal by sea. Sonneratiaalba shares most of its phylogeographic breaks with other mangrove species, suggesting that mangroves were under the influence of similar biogeographic drivers. Nevertheless, differences in the relative significance of the breaks indicated that $S$. alba has a unique biogeographic history characterized by strong genetic divergence at the subregional scale and genetic drift at range limits. Vicariance, oceanic barriers and geographic distance collectively explained the observed genetic pattern in S. alba. The highly restricted gene flow detected in our study supports the fact that the S. alba propagules have limited dispersal distance and highlights the importance of low local retention and high fecundity in ensuring colonization success.

Understanding the underlying mechanisms of genetic divergence not only offers a glimpse of the biogeographic history of a species but also future distributions and evolutionary trajectories [66]. 
This study advances geographic scope of mangrove phylogeography by demonstrating a unique scenario whereby a widespread species has limited dispersal distance and high genetic divergence among populations. Specifically, the presence of range-wide IBD stresses the importance of individual populations in maintaining gene flow. The present expanded range (relative to historical ranges) may promote genetic homogenization in some regions (e.g., the mixing zone between Indian and Pacific Oceans) but intensify diversification in others (e.g., the Coral Sea separating New Caledonia from Australia). Therefore, identification of the evolutionary trajectories of these regions is essential to improve conservation strategies and to understand ecological consequences of future changes. Future studies should focus on mangrove species with varying life history traits and distribution ranges in order to reconstruct the historical biogeography of mangroves as a community and improve our understanding of biogeographic patterns and the future evolution of mangroves.

Supplementary Materials: The following are available online at www.mdpi.com/1999-4907/8/12/483/s1, Table S1: Primers and internal primer pairs (newly designed) used for cpDNA sequencing, Table S2: The 95\% confidence interval of the pairwise $F_{\mathrm{ST}}$ between populations, corrected using the ENA method, Table S3: Estimation of exact $p$-values by the Markov chain method for the Hardy-Weinberg test for heterozygote deficit, Table S4: Estimated null allele frequency for all population-locus combinations, Table S5: Genetic diversity parameters of the eleven microsatellite loci employed in this study, Table S6: Pairwise $F^{\prime}$ ST between population pairs, Figure S1: Plot of $\mathrm{k}$ value against $\Delta K$ from STRUCTURE analysis according to STRUCTURE HARVESTER, indicating that the most likely number of clustersin the total population was two.

Acknowledgments: Samples from Malaysia were collected in collaboration with Universiti Putra Malaysia. Samples from Thailand were collected under the National Research Council of Thailand project ID-2565 "Ecology and Hydrodynamics of Mangroves". The authors thank Latifah Zainal Abidin, Vando Márcio da Silva, Fillipe Cossade Miranda, Masaharu Amano; Lukes Isechal and Jurgenne Primavera, Hoho Takayama and Ketty Beaver for their assistance with field collection. This work was supported by the Singapore Ministry of Education (grant number R154-000-440-112 awarded to E.W.), the Japan Society for the Promotion of Science (JSPS) KAKENHI 22405005, 25290080 and 17H01414 awardedto T.K., Tropical Biosphere Research Center (TBRC) Joint Usage Project Grant 2016 awardedto T.K., Fujiwara Natural History Foundation and KAKENHI 07 J02524 awardedto K.T., and the Indonesia Ministry of National Education(grant number 080/H5.1.R/KEU/2009). A.K.S.W. is supported by the Guangxi University (Nanning) start-up fund and "100 Talents" Program from the provincial government of Guangxi Province. This study is an outcome from the Research Network for Conservation Genetics of Mangroves established by the Graduate School of Science of Chiba University (coordinated by T.K.) through the JSPS JENESYS Programme 2009 and 2011. This study was supported by the Collaborative Research of TBRC, University of the Ryukyus.

Author Contributions: A.K.S.W., J.X.H.T., E.L.W. and T.K. conceived and designed the study. A.K.S.W., K.T., T.A., S.H.M., O., B.A., E.R.A., S.S., M.S., N.X.T., S.G.S., III, O.B.Y., M.N.S., K.K.S., Y.T., Y.W. and T.K collected the plant material. Laboratory procedures were performed by A.K.S.W., J.X.H.T., J.L.C. and K.T. Data analysis was performed by A.K.S.W., J.X.H.T., Y.T., E.L.W. and T.K. The manuscript was written by A.K.S.W., J.X.H.T., Y.T., E.L.W. and T.K. All authors read and approved the final manuscript.

Conflicts of Interest: The authors declare no conflict of interest.

\section{References}

1. Duke, N.; Lo, E.; Sun, M. Global distribution and genetic discontinuities of mangroves—Emerging patterns in the evolution of rhizophora. Trees Struct. Funct. 2002, 16, 65-79. [CrossRef]

2. Cerón-Souza, I.; Gonzalez, E.G.; Schwarzbach, A.E.; Salas-Leiva, D.E.; Rivera-Ocasio, E.; Toro-Perea, N.; Bermingham, E.; McMillan, W.O. Contrasting demographic history and gene flow patterns of two mangrove species on either side of the central american isthmus. Ecol. Evol. 2015, 5, 3486-3499. [CrossRef] [PubMed]

3. Takayama, K.; Tamura, M.; Tateishi, Y.; Webb, E.L.; Kajita, T. Strong genetic structure over the american continents and transoceanic dispersal in the mangrove genus rhizophora (rhizophoraceae) revealed by broad-scale nuclear and chloroplast DNA analysis. Am. J. Bot. 2013, 100, 1191-1201. [CrossRef] [PubMed]

4. Minobe, S.; Fukui, S.; Saiki, R.; Kajita, T.; Changtragoon, S.; Ab Shukor, N.A.; Latiff, A.; Ramesh, B.; Koizumi, O.; Yamazaki, T. Highly differentiated population structure of a mangrove species, Bruguiera gymnorhiza (Rhizophoraceae) revealed by one nuclear gapcp and one chloroplast intergenic spacer TRNF-TRNL. Conserv. Genet. 2010, 11, 301-310. [CrossRef] 
5. Huang, Y.; Tan, F.; Su, G.; Deng, S.; He, H.; Shi, S. Population genetic structure of three tree species in the mangrove genus Ceriops (Rhizophoraceae) from the indo West Pacific. Genetica 2008, 133, 47-56. [CrossRef] [PubMed]

6. Su, G.-H.; Huang, Y.-L.; Tan, F.-X.; Ni, X.-W.; Tang, T.; Shi, S.-H. Genetic variation in Lumnitzera racemosa, a mangrove species from the indo-west pacific. Aquat. Bot. 2006, 84, 341-346. [CrossRef]

7. Wee, A.K.; Takayama, K.; Asakawa, T.; Thompson, B.; Sungkaew, S.; Tung, N.X.; Nazre, M.; Soe, K.K.; Tan, H.T.; Watano, Y.; et al. Oceanic currents, not land masses, maintain the genetic structure of the mangrove Rhizophora mucronata Lam. (Rhizophoraceae) in southeast asia. J. Biogeogr. 2014, 41, 954-964. [CrossRef]

8. Wee, A.K.; Takayama, K.; Chua, J.L.; Asakawa, T.; Meenakshisundaram, S.H.; Adjie, B.; Ardli, E.R.; Sungkaew, S.; Malekal, N.B.; Tung, N.X.; et al. Genetic differentiation and phylogeography of partially sympatric species complex Rhizophora mucronata Lam. and R. stylosa Griff. Using SSR markers. BMC Evol. Biol. 2015, 15, 57. [CrossRef] [PubMed]

9. Tomlinson, P.B. The Botany of Mangroves; Cambridge University Press: Cambridge, UK, 1986.

10. Spalding, M.D.; Kainuma, M.; Collins, L. World Atlas of Mangrove; Earthscan: New York, NY, USA, 2010; p. 304.

11. Yang, Y.; Li, J.; Yang, S.; Li, X.; Fang, L.; Zhong, C.; Duke, N.C.; Zhou, R.; Shi, S. Effects of pleistocene sea-level fluctuations on mangrove population dynamics: A lesson from Sonneratia alba. BMC Evol. Biol. 2017, 17, 22. [CrossRef] [PubMed]

12. Zhou, R.; Ling, S.; Zhao, W.; Osada, N.; Chen, S.; Zhang, M.; He, Z.; Bao, H.; Zhong, C.; Zhang, B.; et al. Population genetics in nonmodel organisms: II. Natural selection in marginal habitats revealed by deep sequencing on dual platforms. Mol. Biol. Evol. 2011, 28, 2833-2842. [CrossRef] [PubMed]

13. Onrizal, O.; Mansor, M. Status of coastal forests of the northern sumatra in 2004's tsunami catastrophe. Biodivers. J. Biol. Divers. 2016, 17, 44-54. [CrossRef]

14. Ball, M.C.; Pidsley, S.M. Growth responses to salinity in relation to distribution of two mangrove species, Sonneratia alba and S. lanceolata, in Northern Australia. Funct. Ecol. 1995, 9, 77-85. [CrossRef]

15. Mazda, Y.; Magi, M.; Ikeda, Y.; Kurokawa, T.; Asano, T. Wave reduction in a mangrove forest dominated by sonneratia sp. Wetl. Ecol. Manag. 2006, 14, 365-378. [CrossRef]

16. Primack, R.B.; Duke, N.C.; Tomlinson, P.B. Floral morphology in relation to pollination ecology in five queensland coastal plants. Austrobaileya 1981, 1, 346-355.

17. Doyle, J.J.; Doyle, J.L. A rapid DNA isolation procedure for small quantities of fresh leaf tissue. Phytochem. Bull. 1987, 19, 11-15.

18. Shinmura, Y.; Wee, A.; Takayama, K.; Asakawa, T.; Yllano, O.; Salmo, S.; Ardli, E.; Tung, N.; Malekal, N.; Onrizal, O.; et al. Development and characterization of 15 polymorphic microsatellite loci in Sonneratia alba (Lythraceae) using next-generation sequencing. Conserv. Genet. Resour. 2012, 4, 811-814. [CrossRef]

19. Hamilton, M. Four primer pairs for the amplification of chloroplast intergenic regions with intraspecific variation. Mol. Ecol. 1999, 8, 521-523. [PubMed]

20. Jordan, W.C.; Courtney, M.W.; Neigel, J.E. Low levels of intraspecific genetic variation at a rapidly evolving chloroplast DNA locus in north american duckweeds (Lemnaceae). Am. J. Bot. 1996, 430-439. [CrossRef]

21. Goudet, J. Fstat (Version 2.9.3.): A Program to Estimate and Test Gene Diversities and Fixation Indices. Available online: http:/ / www2.unil.ch/popgen/softwares/fstat.htm (accessed on 5 June 2014).

22. Dempster, A.P.; Laird, N.M.; Rubin, D.B. Maximum likelihood from incomplete data via the EM algorithm. J. R. Stat. Soc. B Methodol. 1977, 39, 1-38.

23. Chapuis, M.-P.; Estoup, A. Microsatellite null alleles and estimation of population differentiation. Mol. Biol. Evol. 2007, 24, 621-631. [CrossRef] [PubMed]

24. Weir, B.S.; Cockerham, C.C. Estimating f-statistics for the analysis of population structure. Evolution 1984, 38, 1358-1370. [PubMed]

25. Peakall, R.; Smouse, P. Genalex 6.5: Genetic analysis in excel. Population genetic software for teaching and research-An update. Bioinformatics 2012, 28, 2537-2539. [CrossRef] [PubMed]

26. Piry, S.; Luikart, G.; Cornuet, J.-M. Bottleneck: A program for detecting recent effective population size reductions from allele data frequencies. J. Heredity 1999, 90, 502-503. [CrossRef]

27. Meirmans, P.G.; Hedrick, P.W. Assessing population structure: Fst and related measures. Mol. Ecol. Resour. 2011, 11, 5-18. [CrossRef] [PubMed] 
28. Pritchard, J.K.; Stephens, M.; Donnelly, P. Inference of population structure using multilocus genotype data. Genetics 2000, 155, 945-959. [PubMed]

29. Falush, D.; Stephens, M.; Pritchard, J.K. Inference of population structure using multilocus genotype data: Linked loci and correlated allele frequencies. Genetics 2003, 164, 1567-1587. [PubMed]

30. Hubisz, M.J.; Falush, D.; Stephens, M.; Pritchard, J.K. Inferring weak population structure with the assistance of sample group information. Mol. Ecol. Resour. 2009, 9, 1322-1332. [CrossRef] [PubMed]

31. Evanno, G.; Regnaut, S.; Goudet, J. Detecting the number of clusters of individuals using the software Structure: A simulation study. Mol. Ecol. 2005, 14, 2611-2620. [CrossRef] [PubMed]

32. Earl, D.; vonHoldt, B. Structure harvester: A website and program for visualizing structure output and implementing the Evanno method. Conserv. Genet. Resour. 2012, 4, 359-361. [CrossRef]

33. Kopelman, N.M.; Mayzel, J.; Jakobsson, M.; Rosenberg, N.A.; Mayrose, I. Clumpak: A program for identifying clustering modes and packaging population structure inferences across K. Mol. Ecol. Resour. 2015, 15, 1179-1191. [CrossRef] [PubMed]

34. Langella, O. Populations 1.2.28. Population Genetic Software (Individuals or Populations Distances, Phylogenetic Trees); The French National Center for Scientific Research (CNRS): Paris, France, 2002.

35. Manni, F.; Guerard, E.; Heyer, E. Geographic patterns of (genetic, morphologic, linguistic) variation: How barriers can be detected by using Monmonier's algorithm. Hum. Biol. 2004, 76, 173-190. [CrossRef] [PubMed]

36. Dodd, R.S.; Afzal-Rafii, Z.; Kashani, N.; Budrick, J. Land barriers and open oceans: Effects on gene diversity and population structure in Avicennia germinans L. (avicenniaceae). Mol. Ecol. 2002, 11, 1327-1338. [CrossRef] [PubMed]

37. Oksanen, J.; Kindt, R.; Legendre, P.; O'Hara, B.; Stevens, M.H.H.; Oksanen, M.J.; Suggests, M. The vegan package. Community Ecol. Package 2007, 10, 631-637.

38. Kumar, S.; Stecher, G.; Tamura, K. Mega7: Molecular evolutionary genetics analysis version 7.0 for bigger datasets. Mol. Biol. Evol. 2016, 33, 1870-1874. [CrossRef] [PubMed]

39. Posada, D. Jmodeltest: Phylogenetic model averaging. Mol. Biol. Evol. 2008, 25, 1253-1256. [CrossRef] [PubMed]

40. Hasegawa, M.; Kishino, H.; Yano, T.-A. Dating of the human-ape splitting by a molecular clock of mitochondrial DNA. J. Mol. Evol. 1985, 22, 160-174. [CrossRef] [PubMed]

41. Gascuel, O. Bionj: An improved version of the NJ algorithm based on a simple model of sequence data. Mol. Biol. Evol. 1997, 14, 685-695. [CrossRef] [PubMed]

42. QGIS Desktop v2.18.10. Available online: www.qgis.org (accessed on 17 November 2016).

43. DIVA-GIS. Available online: www.diva-gis.org/gdata (accessed on 17 November 2016).

44. Lo, E.Y.; Duke, N.C.; Sun, M. Phylogeographic pattern of Rhizophora (Rhizophoraceae) reveals the importance of both vicariance and long-distance oceanic dispersal to modern mangrove distribution. BMC Evol. Biol. 2014, 14, 83. [CrossRef] [PubMed]

45. Voris, H.K. Maps of Pleistocene sea levels in southeast asia: Shorelines, river systems and time durations. J. Biogeogr. 2000, 27, 1153-1167. [CrossRef]

46. Saint-Cast, F.; Condie, S.A. Circulation Modelling in Torres Strait; Geoscience Australia: Canberra, Australia, 2006.

47. Mirams, A.; Treml, E.; Shields, J.; Liggins, L.; Riginos, C. Vicariance and dispersal across an intermittent barrier: Population genetic structure of marine animals across the Torres strait land bridge. Coral Reefs 2011, 30, 937-949. [CrossRef]

48. Planes, S.; Fauvelot, C. Isolation by distance and vicariance drive genetic structure of a coral reef fish in the Pacific Ocean. Evolution 2002, 56, 378-399. [CrossRef] [PubMed]

49. Chiang, T.Y.; Chiang, Y.C.; Chen, Y.J.; Chou, C.H.; Havanond, S.; Hong, T.N.; Huang, S. Phylogeography of Kandelia candel in east Asiatic mangroves based on nucleotide variation of chloroplast and mitochondrial DNAs. Mol. Ecol. 2001, 10, 2697-2710. [CrossRef] [PubMed]

50. Ngeve, M.N.; Van der Stocken, T.; Menemenlis, D.; Koedam, N.; Triest, L. Contrasting effects of historical sea level rise and contemporary ocean currents on regional gene flow of Rhizophora racemosa in Eastern Atlantic mangroves. PLoS ONE 2016, 11, e0150950. [CrossRef] [PubMed]

51. Lohman, D.J.; Bruyn, M.; Page, T.; Rintelen, K.; Hall, R.; Ng, P.K.; Shih, H.-T.; Carvalho, G.R.; Rintelen, T. Biogeography of the Indo-Australian Archipelago. Annu. Rev. Ecol. Evol. Syst. 2011, 42, 205-226. [CrossRef] 
52. Barber, P.; Palumbi, S.; Erdmann, M.; Moosa, M. Sharp genetic breaks among populations of Haptosquilla pulchella (Stomatopoda) indicate limits to larval transport: Patterns, causes, and consequences. Mol. Ecol. 2002, 11, 659-674. [CrossRef] [PubMed]

53. Benzie, J.A. Major genetic differences between crown-of-thorns starfish (Acanthaster planci) populations in the Indian and Pacific Oceans. Evolution 1999, 53, 1782-1795. [PubMed]

54. Barber, P.H.; Erdmann, M.V.; Palumbi, S.R. Comparative phylogeography of three codistributed Stomatopods: Origins and timing of regional lineage diversification in the Coral Triangle. Evolution 2006, 60, 1825-1839. [CrossRef] [PubMed]

55. Taylor, M.S.; Hellberg, M.E. Genetic evidence for local retention of pelagic larvae in a Caribbean reef fish. Science 2003, 299, 107-109. [CrossRef] [PubMed]

56. Di Nitto, D.; Erftemeijer, P.; van Beek, J.; Dahdouh-Guebas, F.; Higazi, L.; Quisthoudt, K.; Jayatissa, L.; Koedam, N. Modelling drivers of mangrove propagule dispersal and restoration of abandoned shrimp farms. Biogeosci. Discuss. 2013, 10, 1267-1312. [CrossRef]

57. Rabinowitz, D. Dispersal properties of mangrove propagules. Biotropica 1978, 10, 47-57. [CrossRef]

58. Vargas, P.; Nogales, M.; Jaramillo, P.; Olesen, J.M.; Traveset, A.; Heleno, R. Plant colonization across the galápagos islands: Success of the sea dispersal syndrome. Bot. J. Linn. Soc. 2014, 174, 349-358. [CrossRef]

59. Gamache, I.; Jaramillo-Correa, J.P.; Payette, S.; Bousquet, J. Diverging patterns of mitochondrial and nuclear DNA diversity in subarctic black spruce: Imprint of a founder effect associated with postglacial colonization. Mol. Ecol. 2003, 12, 891-901. [CrossRef] [PubMed]

60. Källström, B.; Nyqvist, A.; Åberg, P.; Bodin, M.; André, C. Seed rafting as a dispersal strategy for eelgrass (Zostera marina). Aquat. Bot. 2008, 88, 148-153. [CrossRef]

61. Tsuda, Y.; Nakao, K.; Ide, Y.; Tsumura, Y. The population demography of Betula maximowicziana, a cool-temperate tree species in Japan, in relation to the last glacial period: Its admixture-like genetic structure is the result of simple population splitting not admixing. Mol. Ecol. 2015, 24, 1403-1418. [CrossRef] [PubMed]

62. Arnaud-Haond, S.; Teixeira, S.; Massa, S.I.; Billot, C.; Saenger, P.; Coupland, G.; Duarte, C.M.; Serrao, E.A. Genetic structure at range edge: Low diversity and high inbreeding in southeast asian mangrove (Avicennia marina) populations. Mol. Ecol. 2006, 15, 3515-3525. [CrossRef] [PubMed]

63. De Ryck, D.J.; Koedam, N.; Van der Stocken, T.; van der Ven, R.M.; Adams, J.; Triest, L. Dispersal limitation of the mangrove Avicennia marina at its South African range limit in strong contrast to connectivity in its core East African region. Mar. Ecol. Prog. Ser. 2016, 545, 123-134. [CrossRef]

64. Islam, M.S.; Lian, C.; Kameyama, N.; Hogetsu, T. Low genetic diversity and limited gene flow in a dominant mangrove tree species (Rhizophora stylosa) at its northern biogeographical limit across the chain of three Sakishima islands of the Japanese archipelago as revealed by chloroplast and nuclear SSR analysis. Plant Syst. Evol. 2014, 300, 1123-1136.

65. Sexton, J.P.; McIntyre, P.J.; Angert, A.L.; Rice, K.J. Evolution and ecology of species range limits. Annu. Rev. Ecol. Evol. Syst. 2009, 40, 415-436. [CrossRef]

66. Cordellier, M.; Pfenninger, M. Inferring the past to predict the future: Climate modelling predictions and phylogeography for the freshwater gastropod Radix balthica (Pulmonata, Basommatophora). Mol. Ecol. 2009, 18, 534-544. [CrossRef] [PubMed]

(C) 2017 by the authors. Licensee MDPI, Basel, Switzerland. This article is an open access article distributed under the terms and conditions of the Creative Commons Attribution (CC BY) license (http:// creativecommons.org/licenses/by/4.0/). 